\title{
Biodiesel Production from Rubber Seed Oil Using A Limestone Based Catalyst
}

\author{
Jolius Gimbun ${ }^{1,2}$, Shahid Ali ${ }^{1}$, Chitra Charan Suri Charan Kanwal ${ }^{1}$, Liyana Amer Shah ${ }^{1}$, \\ Nurul Hidayah Muhamad Ghazali ${ }^{1}$, Chin Kui Cheng ${ }^{1,2}$, Said Nurdin ${ }^{1}$ \\ ${ }^{1}$ Faculty of Chemical Engineering and Natural Resources, Universiti Malaysia Pahang, Gambang, Pahang, Malaysia \\ ${ }^{2}$ Centre of Excellence for Advanced Research in Fluid Flow (CARIFF), Universiti Malaysia Pahang, Gambang, Pahang, Malaysia \\ Email: jolius@ump.edu.my
}

Received 2012

\begin{abstract}
This paper presents the potential of limestone based catalyst for transesterification of high free fatty acid (FFA) rubber seed oil (RSO). Pre-calcinated limestone known as clinker was activated using methanol and transesterification was performed under reflux with constant stirring. Mineral composition of the catalyst was analysed using x-ray fluorescence (XRF) with in build x-ray diffraction (XRD). The rubber seed oil was obtained using both microwave and soxhlet extraction using hexane as solvent. FFA content and fatty acid methyl ester content were determined using gas chromatography mass spectrometry (GC-MS). The results showed an efficient conversion (up to 96.9\%) of high FFA rubber seed oil to biodiesel. The results suggest that the catalyst employed in this work is not negatively affected by moisture and free fatty acids and can be recycled very easily without significant loss in its activity. The highest conversion of $96.9 \%$ was achieved from catalyst activated at $700^{\circ} \mathrm{C}$, with catalyst loading of 5 wt. \%; methanol to oil molar ratio of $5: 1$; reaction temperature of $65^{\circ} \mathrm{C}$ and reaction time of 4 hours. The biodiesel produced in this work is within the limits of specification described by American standard test method (ASTM D6751).
\end{abstract}

Keywords: Biodiesel; Microwave Extraction; Cement Clinker; Rubberseed Oil

\section{Introduction}

Biodiesel has been touted as a viable alternative to the traditional petroleum-derived fuels due to environmental concern and sustainability issue. There are several sources of vegetable oil suitable for production of biodiesel such as palm oil, jatropha, soy bean and some selected species of forest seeds. Recently, the European Union is critical to the biofuel production using edible oils such as palm oil, corn, soy bean and maize, which are also consumed as food. These open a new avenue of producing a biodiesel using a non-food source crop such as the seed of the rubber tree (HeveaBrasiliensis). Malaysia has an estimated acreage of 1,021,540 hectares of rubber plantation in 2009 [1] producing an estimated average of more than 120 thousand tons of rubber seeds annually and this project aims to utilize these unused seeds to produce biodiesel. The rubber seed contain approximately about $40 \%$ kernel with $20-25 \%$ moisture. The dried kernel contains $40-50 \%$ of oil [2] which translates to a potential production over 20 million litres of oil per year. The rubber seed oil has a high free fatty acid content, which mean the use of alkaline catalysts such as sodium hydroxide to produce biodiesel is unfavorable [2] because of the formation of relatively large amounts of soaps, leading to product loss and difficulty in the separation and purification of the biodiesel produced [3]. Thus, this work aims to overcome this issue by using a limestone based heterogeneous catalyst.

Heterogeneous base catalysts have advantages of being reusable, noncorrosive, show greater tolerance to water and free fatty acids (FFAs) in feedstock, improve biodiesel yield and purity, have a simpler purification process for glycerol and are easy to separate from the biodiesel product [4-7]. Calcium oxide $(\mathrm{CaO})$ is one of the most common used heterogeneous base catalysts for the transesterification of vegetable oil. Producing biodiesel using $\mathrm{CaO}$ as a solid base catalyst has many advantages, such as higher activity, mild reaction conditions, reusable and low cost [4-7]. Liu et al. [6] shows that $\mathrm{CaO}$ powder can give about $95 \%$ conversion of soybean oil to biodiesel in present of excess methanol $(12: 1)$ at temperature of $60{ }^{\circ} \mathrm{C}$ and reaction time of 3 hours. Hsiao et al. [7] achieved 96.6\% of conversion of soybean oil to biodiesel using a microwave assisted transesterification with $3 \%$ wt. of nanopowderCaO catalyst, methanol/oil ratio of $7: 1$, reaction temperature of $65^{\circ} \mathrm{C}$ and residence time of 1 hour. Use of nanopowdered $\mathrm{CaO}$ has several drawbacks because the nanopowder is not readily available and hence require a high energy to manufacture, furthermore, catalyst recovery or separation will be challenging for nanoparticle. This work aims to prepare a cheaper catalyst from limestone that is easy to recover apart from providing an efficient conversion of vegetable oil to biodiesel.

\section{Materials and Methods}

\subsection{Chemicals}

Chemicals were obtained from various sources namely Merck Malaysia (dried methanol 99.9\%, KOH pellets, hexane HPLC grade), John Kollin Chemicals (ethanol, 99.9\%), R\&M chemicals (diethyl ether), and Sigma-Aldrich (fuller earth, phenolphthalein, methyl heptadecanoate GC grade, n-hexane, acetone). 


\subsection{Rubber Seeds}

The Rubber seeds were collected during maturation period from the rubber tree plantation area located near KampungPandan, Kuantan, Pahang, Malaysia. They were washed to remove dirt and stored at $4^{\circ} \mathrm{C}$ until extraction. Rubber seeds were first de-shelled and dried at $60^{\circ} \mathrm{C}$ for 3 hours. The dried seeds were finely crushed using Waring Commercial Lab Blender and then subjected to drying in an oven at $45^{\circ} \mathrm{C}$ overnight.

\subsection{Soxhlet Extraction (SE)}

Hundreds grams of ground seeds were subjected to a total extraction time of 4 hours at $60^{\circ} \mathrm{C}$ and $250 \mathrm{ml}$ of n-hexane was used as a solvent. After the extraction was completed oil-solvent mixture was subjected to evaporation process under vacuum (BUCHI ${ }^{\circledR}$ Rotavapor R-200) at $60^{\circ} \mathrm{C}$ to evaporate the solvent and recover the extracted oil.

\subsection{Microwave Assisted Extraction (MAE)}

$250 \mathrm{~g}$ of crushed seed was put into a glass jar and the oil was extracted with $500 \mathrm{ml}$ of $\mathrm{n}$-hexane for 30 minutes at $64^{\circ} \mathrm{C}$ and power of 200W using the Milestone Micro synth ATC-FO 300. The n-hexane was then separated from the crude rubber seed oil using a rotary evaporator.

\subsection{Analysis of Rubber Seed Oil and Biodiesel}

The extracted RSO and biodiesel was being analyzed for its lipid and ester content respectively. Standard ASTM D6751 methods were being used to find, acid value (ASTM D664), calorific value (ASTM D240), kinematic viscosity (ASTM D445), moisture content (ASTM D2709), flash point (ASTM D93), specific gravity (ASTM D287) and cetane number (ASTM D613).

\subsection{Catalyst Activation}

The limestone based cement intermediate called clincker was obtained from Pahang Cement atKuantan Malaysia. Detail chemical composition of the clinker obtained from X-ray florescence with in-build XRD (ARL 8660S) is shown in Table 2 which indicates a significant $\mathrm{CaO}$ content $(66.6 \%)$ useful for transesterification process. Clinker was crushed and ground to reduce the particle size around $200 \mu \mathrm{m}$ to ensure a large surface area per unit mass. The catalyst activation was performed by soaking with methanol followed by calcination at $700^{\circ} \mathrm{C}$ for 7 hours in the furnace (Carbolite, CWF1215).

\subsection{RSO and Biodiesel Composition Analysis}

Oil and FAME composition of seed oil was determined using gas chromatography mass spectroscopy (GC-MS) according to ASTM D6584. Samples from the extraction and biodiesel production process were taken and dissolved in HPLC grade hexane before being injected into the GC-MS. Tri-acylglycerides (TAG) analysis was performed on Agilent 7890A GC System

Table 1. Clinker analysis with XRF-XRD.

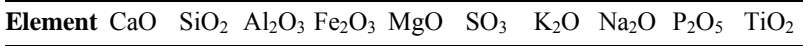

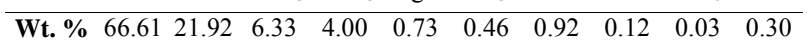

equipped with Agilent 7683B Series Injector, 5975C Inert MSD and a DB-1 column $(30 \mathrm{~m} \times 0.25 \mathrm{~mm} \times 0.25 \mu \mathrm{m}$ films $)$, with a temperature range of $60-340^{\circ} \mathrm{C}$, while the FAME produced were analyzed on HP-5 column $(30 \mathrm{~m} \times 0.25 \mathrm{~mm} \times 0.25 \mu \mathrm{m})$ with a temperature range of $60^{\circ} \mathrm{C}$ to $325^{\circ} \mathrm{C}$. Identification of the peaks was performed by comparing retention times with those of library standards analyzed under the same conditions. FAME and fatty acid composition was determined as in Table 3 . The most abundant fatty acids in RSO were linoleic, stearic, and palmitic acids. While the FAME is mainly of methyl linolelaidate and methyl vaccinate.

\subsection{Transesterification and Purification of Rubber Seed Oil}

The catalyst of various amount ranged from 3 to $7 \mathrm{wt} \%$ was dispersed in methanol at temperature ranged from 50 to $70^{\circ} \mathrm{C}$ for a period of time prior to contact with the preheated feedstock, providing a robust transesterification catalyst system. Transesterification were performed at various residence time ranged from 0.5 to 4 hours with aid of agitation. Water soluble methanol and glycerol were removed by washing intensely with water. The biodiesel produced was filtered to remove the catalyst and residual methanol was vacuum evaporated. Fuller earth was used to reduce the moisture content of the product. Eppendorf 5810R centrifuge was used to remove the fuller earth, residual catalyst and glycerol followed by analysis of its properties according to ASTM D6751 standard. All experiments were repeated three times, and the value reported in this paper was the average value.

Table 2. FAME and Fatty Acid composition of RSO.

\begin{tabular}{lcc}
\hline \multicolumn{1}{c}{ Properties } & This work & Ramadhas et al. [2] \\
\hline Fatty acid composition (\%) & & \\
Palmitic acid C16:0 & 10.29 & 10.2 \\
Stearic acid C18:0 & 8.68 & 8.7 \\
Oleic acid C18:1 & 20.07 & 24.6 \\
$\quad$ Linoleic acid C18:2 & 58.5 & 39.6 \\
Linolenic acid C18:3 & 0.8 & 16.3 \\
FAME content (\%) & & \\
Methyl palmitate & 7.7 & \\
Methyl stearate & 3.9 & \\
Methyl linolelaidate & 43.2 & \\
Methyl vaccenate & 45.1 & \\
Others & 3.1 & \\
Specific gravity & 0.92 & 0.91 \\
Calorific value (MJ/kg) & 38.96 & 37.5 \\
Acid value (mg KOH/g) & 35.14 & 34 \\
\hline
\end{tabular}

Table 3. Properties of Methyl Esters from Rubber Seed Oil.

\begin{tabular}{lcccc}
\hline \multicolumn{1}{c}{ Properties } & ASTM & Limits & This work & $\begin{array}{c}\text { Ramadhas } \\
\text { et al. [2] }\end{array}$ \\
\hline Calorific value $(\mathrm{MJ} / \mathrm{Kg})$ & $\mathrm{D} 240$ & -- & 39.37 & 36.5 \\
Kinematic Viscosity, & $\mathrm{D} 445$ & $1.9-6.0$ & 4.64 & 5.81 \\
$40^{\circ} \mathrm{C}\left(\mathrm{mm}^{2} / \mathrm{s}\right)$ & $\mathrm{D} 93$ & $>130$ & 154.6 & 130 \\
Flash point $\left({ }^{\circ} \mathrm{C}\right)$ & $\mathrm{D} 287$ & $0.82-0.9$ & 0.87 & 0.87 \\
Specific Gravity & $\mathrm{D} 664$ & $<0.50$ & 0.07 & 0.8 \\
Acid value $(\mathrm{mg} \mathrm{KOH} / \mathrm{g})$ & $\mathrm{D} 613$ & $>47$ & 66.2 & 43 \\
Cetane number & & & &
\end{tabular}




\section{Results and Discussions}

\subsection{Comparison of Soxhlet and Microwave Asissted Extraction}

Comparison of extraction efficiency of rubber seed oil using soxhlet and microwave extraction is presented in Figure 1. The results suggest that microwave extraction is better than the conventional soxhlet method because the yield of oil extracted is much higher at $40 \%$ compared to the soxhlet at $36 \%$. Furthermore, microwave extraction is much faster at 15 minutes compared to about 6 hours for the soxhlet method. This is due to microwave heating which interact selectively with the free solvent molecules present in the homogenized solution; this leads to localized heating, and the temperature increases rapidly. Thus, such systems undergo a dramatic expansion, with subsequent rupture of cell walls, allowing the oil to flow outwards from the inside of finely crushed seeds [8]. In contrast the soxhlet extraction is diffusion driven where the solvent diffuses into the matrix and extracts the components by solubilization, hence a slow process. The yield of oil recovered from rubber seed in this work is in agreement with earlier work by Ramadhas et al. [2]. The MAE method is more efficient in terms of yield and time consumption for the extraction process. Therefore, microwave extraction method will be used for the remainder of this work.

\subsection{Influence of Methanol to Oil Molar Ratio}

Theoretically the stoichiometry of transesterification reactions requires 3 mole of alcohol for every mole of triglyceride in order to produce 3 mole of methyl ester and 1 mole of glycerol as by product. However, it is not always possible to achieve an optimum transesterification using a 3:1 ratio since yield of glycerol and conversion is not always perfect.Results in Figure 2 shows the increasing trend of conversion rate with the methanol/oil molar ratio ranging from 2:1 to 4:1, but afterwards shows a slight decline in conversion rate with the methanol/oil molar ratio going from $5: 1$ to $6: 1$. At first, excess methanol increases the solubility of the by-product (glycerol) [7] which then may initiate the reversible reaction to reduce the conversion. The optimum methanol/oil molar ratio was observed at 4:1. Excess methanol can be removed easily by washing withwater, and its residual may be removed using rotary evaporator.

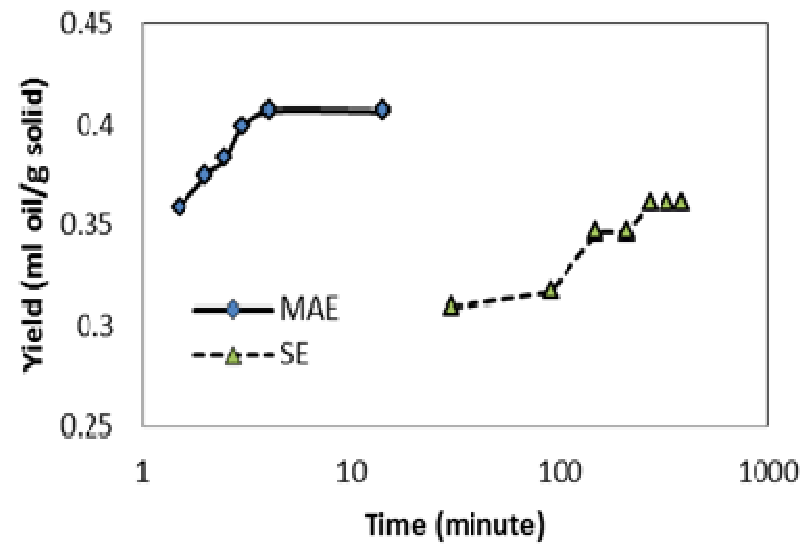

Figure 1. Comparison of soxhlet and microwave assisted extraction.

\subsection{Influence of Catalyst Loading}

Figure 3 shows the conversion of RSO to biodiesel increases when the amount of catalyst increased from 2.0 to $6.0 \mathrm{wt} . \%$ with the methanol to oil ratio of $4: 1$, but decreased when the amount of catalyst exceeded $6.0 \mathrm{wt} . \%$. This is due to reversible nature of the transesterification process [9] whereby the catalyst concentration levels greater than $6 \%$ may have favored the backward reaction. The results suggest that optimum catalyst loading for RSO transesterification is 6 wt.\% with conversion of $92.3 \%$.

\subsection{Influence of Temperature}

Generally, as the reaction temperature increases, the rate of reaction increases as they are affected by temperature through the Arrhenius equation. Figure 4 shows the conversion increases from $65.4 \%$ to $96.9 \%$ when the temperature increased

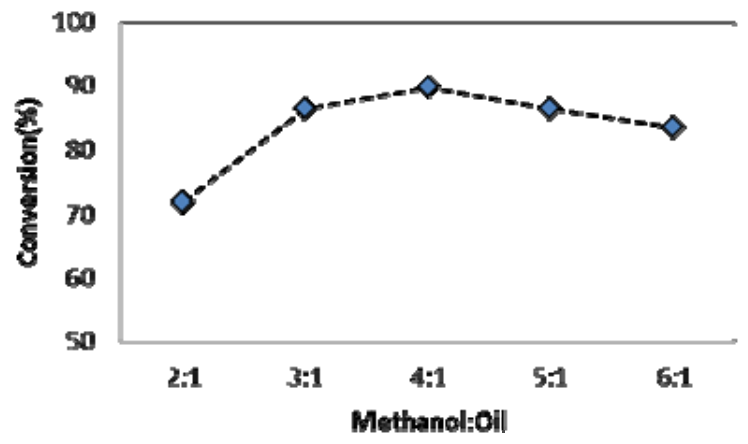

Figure 2. Effect of methanol to oil ratio ( 4 wt. $\%$ catalyst, $55^{\circ} \mathrm{C}$ ).

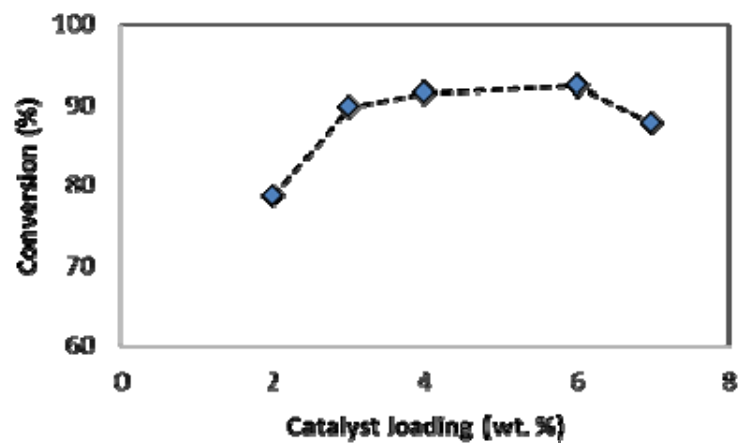

Figure 3. Effect of catalyst loading (Temperature $55^{\circ} \mathrm{C}$, Methanol:Oil 4:1).

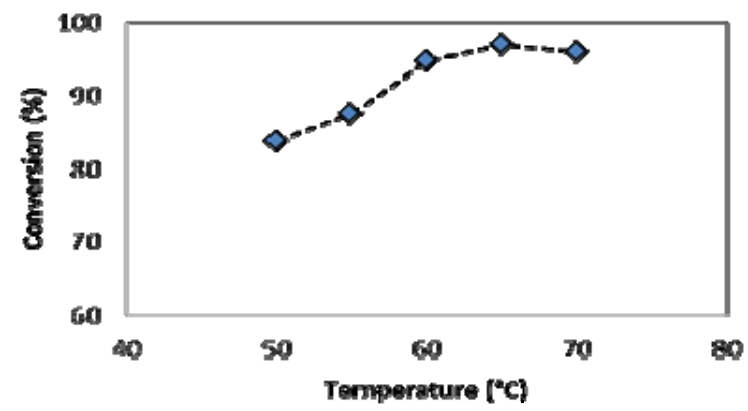

Figure 4. Effect of temperature to (methanol:oil 4:1, catalyst loading $5 \%$ wt.). 


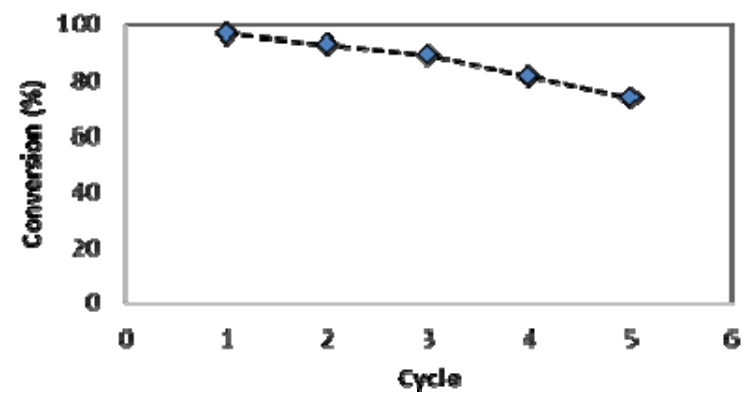

Figure 5. Catalyst recycability study.

from $40^{\circ} \mathrm{C}$ to $65^{\circ} \mathrm{C}$. Higher temperature improves the efficiency of transesterification, which in turn enhances the RSO conversion. However, increasing the temperature above $65^{\circ} \mathrm{C}$ does not significantly affect the RSO conversion; in fact conversion reduces slightly to $95.8 \%$ when temperature increases to $70^{\circ} \mathrm{C}$. This is due to methanol evaporation at temperature higher than $64.7^{\circ} \mathrm{C}$ (methanol boiling point) and hence oil to methanol ratio cannot be maintained to achieve a desirable reaction. Optimumtemperature for RSO transesterification with limestone based catalyst is around $65^{\circ} \mathrm{C}$.

\subsection{Catalyst Recycability}

The most important advantage of using heterogeneous material as catalysts is the ability to recycle and reuse. The catalyst was collected for reuse using a filter paper and washed with acetone to remove the impurities of the mixture at the end of the reaction. The catalyst was reused up to 5 times for rubber seed oil transesterification with some reduction (about 5\% per cycle) in conversion at the $3^{\text {rd }}, 4^{\text {th }}$ and $5^{\text {th }}$ cycle as shown in Figure 5. The catalyst in this work has a comparable reuse efficiency as the metal based catalyst, e.g. hydrotalcite particles with $\mathrm{Mg} / \mathrm{Al}$ used by Deng et al. [10] for transesterification of Jatropha oil. The decline may be attributed to entrapment of glycerol on its active surface. In comparison with the recyclability of other solid metal based catalysts [10], the cement clinker catalysts showed an unprecedented stability and recyclability for biodiesel synthesis.

\subsection{Properties of Methyl Esters from Rubber Seed Oil}

The fuel properties of FAME produced in this work is compared with Ramadhas et al. [2], who studied rubber seed oil transesterification using a homogeneous catalyst $(\mathrm{NaOH})$. This work is a single step method which involved only the transesterification process unlike the two-step method employed by Ramadhas et al. [2]. As shown in Table 1, all the properties are within the biodiesel specification described by ASTM D6751. The calorific value of in this work seems to be slightly higher than the previous work by Ramadhas et al. [2]; furthermore, the kinematic viscosity and acid value are very much lower in comparison. The cetane number of 66.2 for biodiesel produced in this work is better than the previous work [2] and compliance to the ASTM standard. The good biodiesel property in this work is attributed to extensive the purification step undertaken to the FAME which include among other washing, centrifugation and bleaching.

\section{Conclusions}

Microwave assisted extractionis more efficient in terms of yield and time consumption as it can achieve a maximum extraction within 4 minutes, which cannot be achieved through conventional soxhlet method even after 6 hours. The limestone based catalyst derived from cement clinker showed an efficient conversion (up to $96.9 \%$ ) of high FFA rubber seed oil to biodiesel. The results suggest that the catalyst employed in this work is not negatively affected by moisture and free fatty acids and can be recycled very easily without a significant loss in its activity. The biodiesel produced in this work is within the limits of specification described by ASTM D6751.

\section{Acknowledgements}

ShahidAli thanks Universiti Malaysia Pahangfor the GRS100348 funding. We thank Ministry of Higher Education Malaysia for the MTUN COE grant RDU121216.

\section{REFERENCES}

[1] Malaysia rubber board, "Natural rubber statistic 2011", http://www.lgm.gov.my, (10 June 2012)

[2] A. S. Ramadhas, S. Jayaraj, and C. Muraleedharan, "Biodiesel production from high FFA rubber seed oil", Fuel, vol. 84, pp.335-340, March 2005.

[3] M. Kouzu, T. Kasuno, M. Tajika, S. Yamanaka, and J. Hidaka, "Active phase of calcium oxide used as solid base catalyst for transesterification of soybean oil with refluxing methanol", Appl. Catal. A: Gen., vol.334, pp. 357-365, 2008.

[4] A. Kawashima, K. Matsubara, K. Honda, "Development of heterogeneous base catalysts for biodiesel production”, Bioresource Technology, vol. 99, pp. 3439-3443, June 2008.

[5] A. Kawashima, K. Matsubara, K. Honda, "Acceleration of catalytic activity of calcium oxide for biodiesel production", Bioresource Technology, vol. 100, pp. 696-700, January 2009.

[6] X. Liu, H. He, Y. Wang, S. Zhu, X. Piao, "Transesterification of soybean oil to biodiesel using $\mathrm{CaO}$ as a solid base catalyst", Fuel, vol. 87, pp. 216-221, February 2008.

[7] M.-C. Hsiao, C.-C. Lin, and Y.-H. Chang, "Microwave irradiation-assisted transesterification of soybean oil to biodiesel catalyzed by nanopowder calcium oxide", Fuel, vol. 90, pp. 1963-1967, May 2011.

[8] C. S. Eskilsson and E. Björklund, "Analytical-scale microwaveassisted extraction", Journal of Chromatography A, vol. 902, pp. 227-250, November 2000.

[9] D. Darnoko, "Continuous production of methyl esthers from oil palm and recovery of beta-carotene by membrane technology", $\mathrm{PhD}$ thesis, University of Illinois, Urbana, 1999.

[10] X Deng, Z Fang, Y-H Liu, C-L Yu, "Production of biodiesel from Jatropha oil catalyzed by nanosized solid basic catalyst", Energy, Vol. 36, pp.777-784,February 2011. 